\title{
Editorial:
}

\section{Trends in Digital Marketing for Biodiversity Conservation}

\author{
Tendencias en marketing digital para promover la conservación de la \\ biodiversidad
}

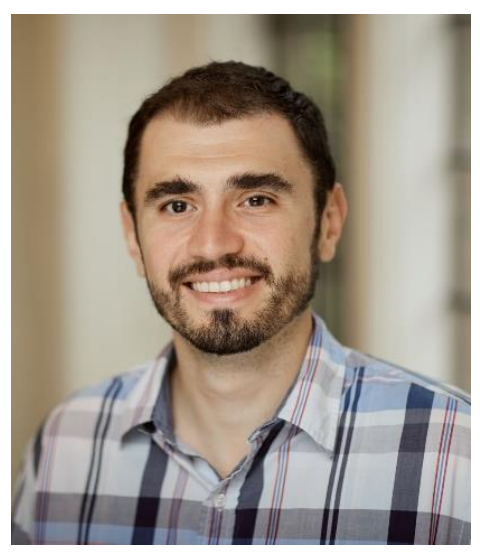

Diogo Veríssimo

Research Fellow - University of Oxford

Director of Conservation Marketing, On the Edge Conservation

United Kingdom

E-mail: verissimodiogo@gmail.com

https://doi.org/10.22430/24223182.1957

The COVID-19 pandemic has kept millions of people in many countries confined to their homes for months, a limitation that has obviously had a big impact on our ability to access nature (O'Brien \& Forster, 2020). This increase in time spent indoors has led to higher engagement with digital media (Newzoo, 2020), a trend unlikely to go away after the end of the pandemic. In this context, digital marketing strategies have become more important than ever. This is also true in the realm of biodiversity conservation, where professionals work to influence audiences worldwide and both preserve the diversity of life on Earth and ensure humanity has the ecosystem services we need to survive. In the absence of opportunities to go outside, conservationists must adopt innovative strategies to maintain the link between people and nature. In the last few years, there have been a number of important innovations in the way conservationists communicate, and which may allow us to influence audiences that have historically been out of reach of traditional outreach strategies. Below, I present some of the most thought-provoking. 


\section{Mobile games}

Digital games have become a dominant form of entertainment, with those played on mobile devices (i.e., smartphones or tablets) expected to be the leading market segment in the next decade (Newzoo, 2020). This growth has also been experienced in the so-called "serious games" segment, which includes not-for-profit games aiming to solve real world problems (Annetta, 2010; Sandbrook et al., 2015). In the context of biodiversity conservation, the potential of digital games has been long recognised (Greenwood, 2012). Nevertheless, their use has remained small scale, with limited investment and a lack of research, particularly on impact assessments that allow for a better understanding of what and how digital games can truly deliver.

There are, however, indications that this is changing, with recent impact evaluations uncovering encouraging effects (e.g., Dunn \& Veríssimo, 2020) and major organisations such as National Geographic supporting the development of new games (Machemer, 2020). This could herald the mainstreaming of mobile games to promote biodiversity conservation, a promising trend given the mounting body of evidence in areas as diverse as healthy eating, sexual health, language training, and physical fitness, which suggests that serious games can deliver positive outcomes (Boyle et al., 2016).

In terms of game design, advances in hardware are likely to increase accessibility of games that use augmented and virtual reality, potentially allowing users to experience biodiversity in a realistic fashion without having to leave their homes. Yet, there is a lack of understanding around the costeffectiveness of these experiences in the context of biodiversity conservation, particularly due to their substantial development cost.

\section{Social media advertising}

Digital channels will soon dominate advertising, with the last decade seeing a tremendous growth in this field (Dentsu Aegis Network, 2020). Within digital, social media is the area where advertising spend has experienced the strongest growth (Dentsu Aegis Network, 2020). This rise in importance is largely a function of the unprecedent ability of social media to segment and reach audiences, thus delivering value for money to a range of organisations operating at different scales. While organisations working in the biodiversity conservation arena are no strangers to the use of social media - with many boasting large followings - , the use of paid advertising has been largely focused on fundraising. This neglects the potential that social media advertising can have in influencing individuals and groups, and thus mitigate the key threats to nature, all of which stem from human behaviour. That said, there are signs of change. For example, Doughty et al. (2020) combined different types of digital advertising as part of an intervention to reduce the use of saiga horn for medicinal purposes in Singapore and found that Facebook was the most cost-effective platform and the one providing the most detailed analytics. This suggests that social media could potentially replace the traditional channels that conservationists have thus far focused on to get their messages out, although a deeper examination of the potential of different social media platforms is yet to be carried out. 


\section{Virtual influencers}

The rise of influencer marketing, which focuses on individuals with a substantial online following (often on social media) who promote products and brands, has changed the way businesses communicate with consumers (Kadekova \& Holienčinova, 2018). This trend is paralleled in the context of biodiversity conservation, with environmental non-government organisations, for example, increasingly relying on celebrities to make their messages heard (Olmedo et al., 2020). One aspect that, however, remains largely unexplored is the use of virtual influencers, those influencers that are based on Computer-Generated Imagery (CGI) or artificial intelligence, as opposed to a real person. Some of these influencers, such as Lil Miquela, a fictional 19-year-old American female character, have already achieved notoriety, gathering millions of fans online and mixing promotional posts for luxury brands like Prada with social activism initiatives in support of causes like Black Lives Matter (Moustakas et al., 2020).

Although most virtual influencers to date have been human in appearance, this is a potential new avenue that could be explored by those aiming to promote the conservation of biodiversity. In the United Kingdom, for instance, On the Edge Conservation launched three virtual animal influencers last year with the goal of getting more attention for some of the most unique, endangered, and overlooked species on the planet (Figure 1).
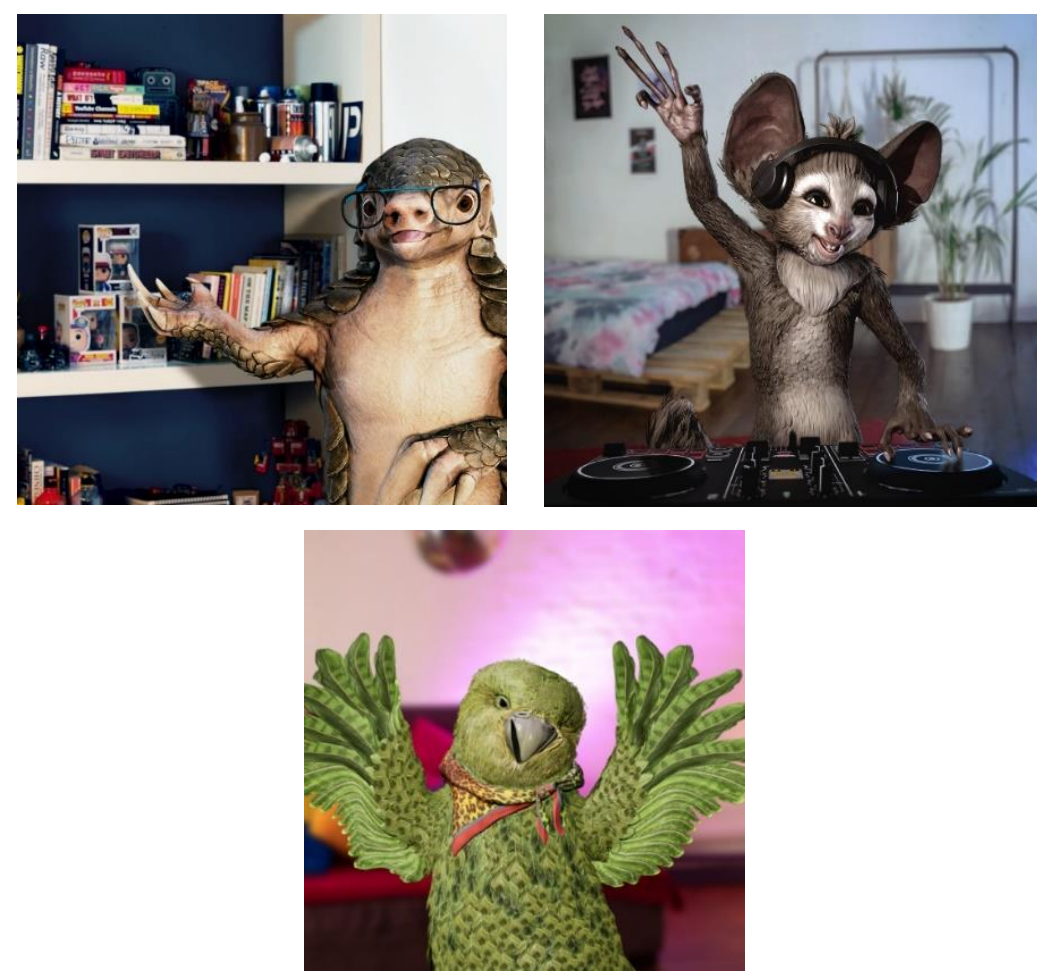

Figure 1. Virtual influencers -Eric (top left), Lexi (top right), and Tegan (bottom)- designed by On the Edge Conservation to drive pro-environmental behaviours

Figura 1. Influenciadores virtuales -Eric (parte superior izquierda), Lexi (parte superior derecha) y Tegan (parte inferior)- diseñados por On the Edge Conservation para promover comportamientos proambientales Source: https://www.ontheedge.org/ 
Virtual influencers have the distinct advantage of giving their creators full control over their messaging and actions. Yet, the potential for these messengers to be perceived as inauthentic has been highlighted as an important challenge (Kadekova \& Holienčinova, 2018; Moustakas et al., 2020) and an aspect that conservationists will need to tackle if these messengers are to be used effectively. This could theoretically be even more of a concern for animal influencers, which are even further removed from humans, and so there is a critical need for audience research into this issue.

\section{Where next?}

The use of digital marketing tools will only increase as the world's population, together with the economy, increasingly moves online. Even though none of these tools are silver bullets, the current biodiversity crisis suggests that they should be closely examined and evaluated to provide an understanding of their true potential. Digital is the future and any messages worth communicating need to have a strong presence in this space if they are to fulfill their goals.

\section{REFERENCES}

Annetta, L. A. (2010) The "I's" have it: A framework for serious educational game design. Review of General Psychology, v. 14, n. 2, 105-113. https://doi.org/10.1037/a0018985

Boyle, E. A.; Hainey, T.; Connolly, T. M.; Gray, G.; Earp, J.; Ott, M.; Lim, T.; Ninaus, M.; Ribeiro, C.; Pereira, J. (2016). An update to the systematic literature review of empirical evidence of the impacts and outcomes of computer games and serious games. Computers \& Education, v. 94, 178-192. https://doi.org/10.1016/i.compedu.2015.11.003

Dentsu Aegis Network. (2020). Global Ad Spend Forecasts January 2020. URL

Doughty, H.; Wright, J.; Veríssimo, D.; Lee, J. S. H.; Oliver, K.; Milner-Gulland, E. J. (2020) Strategic advertising of online news articles as an intervention to influence wildlife product consumers. Conservation Science and Practice, v. 2, n. 10, e272. https://doi.org/10.1111/csp2.272

Dunn M.; Veríssimo, D. (2020). Evaluating the impact of a mobile conservation game on players' support for nature conservation. SocArXiv OSF Preprints. https://doi.org/10.31219/osf.io/xuvd4

Greenwood, C. (2012). Fate of The World: computer gaming for conservation? Oryx, v. 46, n. 1, 1414. https://doi.org/10.1017/S0030605311002158

Kadekova, Z.; Holienčinova, M. (2018). Influencer marketing as a modern phenomenon creating a new frontier of virtual opportunities. Communication Today, v. 9, n. 2, 90-104. URL

Machemer, T. (2020). Can video games make people care abut wildlife conservation? $\underline{\text { URL }}$ 
Moustakas, E.; Lamba, N.; Mahmoud, D.; Ranganathan, C. (2020). Blurring lines between fiction and reality: Perspectives of experts on marketing effectiveness of virtual influencers. 2020 International Conference on Cyber Security and Protection of Digital Services (Cyber Security). IEEE. https://doi.org/10.1109/CyberSecurity49315.2020.9138861

Newzoo. (2020). Newzoo Global Games Market Report 2020 - Light Version. URL

O'Brien, L.; Forster, J. (2020) Engagement with nature and Covid-19 restrictions. Quantitative analysis 2020. URL

Olmedo, A.; Milner-Gulland, E. J.; Challender, D. W. S.; Cugnière, L.; Dao, H. T. T.; Nguyen, L. B.; Nuno, A.; Potier, E.; Ribadeneira, M.; Thomas-Walters, L.; Wan, A. K. Y.; Wang, Y.; Veríssimo, D. (2020). A scoping review of celebrity endorsement in environmental campaigns and evidence for its effectiveness. Conservation Science and Practice, v. 2, n. 10, e261. https://doi.org/10.1111/csp2.261

Sandbrook, C.; Adams, W. M.; Monteferri, B. (2015) Digital games and biodiversity conservation. Conservation Letters, v. 8, n. 2, 118-124. https://doi.org/10.1111/conl.12113 